\title{
Topographic Controls on the Distribution of Summer Monsoon Precipitation over South Asia
}

\author{
Moetasim Ashfaq $^{1}$ (1)
}

Received: 18 November 2020 / Accepted: 2 December 2020 / Published online: 22 December 2020

(c) Oak Ridge National Laboratory 2020, under exclusive licence to King Abdulaziz University and Springer Nature Switzerland AG 2020

\begin{abstract}
We use a high-resolution $(9 \mathrm{~km})$ one-way nested regional climate modeling framework to systematically evaluate individual and aggregate roles of various components of topography in the precipitation distribution during South Asian Summer Monsoon (SASM). While it is not the arrival but the north-northwestward extent of summer monsoon precipitation that is regulated by the presence of elevated surfaces in South Asia, both the thermal and mechanical topographic forcing play a role. Topography not only provides mechanical uplifting and prevents dry air entrainment, it also helps regulate the strength of upper level anticyclone and tropical easterly jet, all of which are necessary to sustain a conducive environment for monsoon precipitation in the South Asian summer. In turn, precipitation feedbacks positively by accelerating the tropospheric diabatic warming through atmospheric latent heating and by maintaining the moisture supply through local recycling. Modifications in the topography, particularly the removal of the Tibetan Plateau, substantially modulates the moist flow in the lower troposphere and the anticyclonic circulation in the upper troposphere to an extent that the northern branch of SASM becomes substantially weaker. These changes give way to negative precipitation anomalies and eventually to an environment where the cycle of feedbacks that runs the process of monsoon progression over land becomes inefficient. The design of topographic modification experiments can influence precipitation response; therefore, we advise caution in the interpretation of these and previously reported results.
\end{abstract}

Keywords South Asian summer monsoon · Topographic forcing · Tibetan Plateau

\section{Introduction}

The debate on the role of topography in the development and maintenance of the South Asian Summer Monsoon (hereafter SASM) remains unresolved. It has progressively swayed between the viewpoint that topography acts as an elevated heat source and the viewpoint that it acts as a barrier to prevent thermal exchanges between the cold and dry extratropics and the warm and moist tropics/sub-tropics (e.g., Acosta and Huber 2020, Boos and Kuang 2010, 2013, Chakraborty et al. 2006, Chen et al. 2014, He et al. 2018, Li and Yanai 1996, Ma et al. 2014, and Wu et al. 2012). Interestingly, these strikingly different conclusions are often a result of sensitivity experiments of broadly similar nature. Not a long time ago, the Tibetan Plateau (TP) was widely

Moetasim Ashfaq

mashfaq@ornl.gov

1 Computational Sciences and Engineering Division, Oak Ridge National Laboratory, Oak Ridge, TN, USA believed to have a key role in shaping climate over South Asia (e.g., Fu and Fletcher 1985, Hahn and Manabe 1975, Lau et al. 2006, Li and Yanai 1996, Wu et al. 1997, and Wu and Zhang 1998). In 2010, Boos and Kuang (2010; hereafter BK10) showed that topographic thermal forcing was not the cause of the meridional differential heating in the troposphere and that northern branch of SASM could be maintained without it. Through topographic modification in a General Circulation Model (GCM), they noted that mountains acted as a mechanical insulator, not as a thermal forcing, and that only thin belt of the Himalayas, Karakorum and Hindukush (HKH) was sufficient to prevent the ventilation of warm and moist monsoon air by cold and dry extratropical air. It ignited a new debate on the role of topography in the distribution of summer precipitation over South Asia. In 2012, Wu et al. (2012; hereafter W12) suggested that BK10 did not fully remove the elevated thermal forcing in their modified topography experiments. Using a different GCM, they showed that when sensible heating over the HKH was removed in the BK10-modified topography experiment 
(where only the HKH were kept and the TP was removed), they could not reproduce the northern branch of monsoon as it was in the case of BK10. Based on their findings, they suggested that while northern branch of SASM could be reproduced without the presence of TP, it only happened if thermal forcing (sensible heating) over the Himalayas was present. W12 also suggested a role of the Iranian Plateau as a thermal forcing. In response to W12, Boos and Kuang (2013) showed in new sensitivity experiments that sensible heating along the slopes of HKH was not as important as it was suggested by W12 and that its impact was mostly localized. Boos and Kuang (2013) later reinforced their viewpoint in another co-authored study using high-resolution global Weather Research and Forecast (WRF) model configuration (Ma et al. 2014). More recently, using a high-resolution configuration of a GCM, Acosta and Huber (2020) reignited this debate by arguing that topography redirects moisture flow and provides orographic lift, but it does not have a role in the onshore moisture advection. They also suggest that the Iranian Plateau acts as a gatekeeper and its removal allows entrainment of dry air from northwest Asia.

Nonetheless, what has often lacked in these studies is a discussion on the relative role of individual mountain ranges, which encompass this region, in the spatiotemporal distribution of monsoon precipitation. There are several mountain ranges that isolate South Asia from the surrounding regions, including the Himalayas in the north, Karakoram and Hindukush in the west-northwest, and the Arakan mountains in the east, which respectively provide a natural divide from East Asia, West Asia and Southeast Asia. Similarly, the Western Ghats separate the coastal plains from the Deccan Plateau in southwest India. The orographic uplift and rain shadowing provided by many of these mountain ranges is manifested in the observed spatial distribution of precipitation maxima and minima across South Asia. However, it remains unclear as to why the broadly similar GCM-based experiments in various studies are unable to establish a robust understanding of the role of topography as an insulator, deflector or thermal regulator in shaping SASM (e.g., Acosta and Huber 2020, Boos and Kuang 2010, 2013, and Wu et al. 2012). Moreover, a systematic evaluation focused on the individual and aggregate impacts of these elevated surfaces on dynamic and thermodynamic controls of the summer monsoon precipitation is currently lacking.

As previously noted, most of the studies investigating the role of topography in South Asia make use of GCMs (e.g., Acosta and Huber 2020, Boos and Kuang 2010, 2013, Chakraborty et al. 2006, Chen et al. 2014, and Wu et al. 2012). Such an approach allows feedbacks to the largescale atmospheric mechanisms beyond the region of interest, which in turn can exert influence on the precipitation regulating processes over the study domain. The possibility of two-way feedbacks between the large-scale and regional/ local-scale processes in an experimental design provides physical consistency. However, GCMs often exhibit biases in the representation of observed relationships between the large-scale and regional/local-scale processes, particularly over the South Asian summer monsoon region (e.g., Almazroui et al. 2020a, Ashfaq et al. 2017, Boos and Hurley 2013, and Sperber et al. 2013), which can lead to unwarranted feedbacks in sensitivity experiments. While the lack of orographic detail in GCM-based sensitivity experiments is another issue that limits what can be inferred about the role of topography in South Asia from such investigations, GCM performance over South Asia is often not a function of their horizontal grid spacing (e.g., Ashfaq et al. 2017).

Here, we use a high-resolution one-way nested regional climate model (RCM) within a perfect lateral and lower boundary forcing framework to systematically evaluate the individual and aggregate roles of various components of topography in the precipitation distribution during SASM. The use of reanalysis at the lower and lateral boundaries of an RCM is termed as "perfect" forcing condition because it provides the most realistic estimates of prognostic climate variables in space and time (Giorgi 2019). The one-way nesting approach (no feedbacks between the RCM and the boundary forcing) should allow for the isolation of anomalies in the precipitation distribution which are directly a result of orographically induced changes in the regional monsoon dynamics and thermodynamics from the ones which can arise as a result of indirect feedbacks between the large-scale and regional/local-scale processes. Moreover, unlike the GCM-based modeling studies where simulations have been conducted continuously over multiple years, our experiments are initialized every year separately before the monsoon season. Topographic modifications have the potential to induce soil moisture anomalies in the preceding months, which can lead to the possibility of land surface memory effects during the summer season. Therefore, summer-only runs eliminate the possibility of such indirect influences on the simulated results. Furthermore, perfect lateral and lower boundary conditions minimize errors in the large-scale forcing that may impact simulated responses within the study domain. Overall, this modeling framework attempts to reduce simulation errors and excludes indirect feedbacks in space and time, both of which can introduce complex interaction that are difficult to disentangle in such experiments. The design of experiments is not intended to suggest that the indirect feedbacks are not important, but to ensure that the simulated responses are easily attributable. Lastly, our analyses are based on the entire summer season that stretches from June to September. The previous studies on the related topic have often considered June-August as the SASM period in their analyses (e.g., Acosta and Huber 2020, Boos and Kuang 2010, 2013, and Wu et al. 2012). However, monsoon does not onset over west-northwest 
South Asia until the start of July (Wang and Ho 2002). Therefore, the period from June to August is not a robust representation of the monsoon rainy season over South Asia.

\section{Data and Methods}

\subsection{Model and Data}

We employ the WRF model version 3.5 (Skamarock et al. 2008) over a region covering South Asia and surrounding areas (Fig. 1a). The limited area configuration of the WRF model and other RCMs have been commonly used over South Asia for climate studies (e.g., Ashfaq et al., 2009, Devanand et al. 2019, Karmacharya et al. 2017, Hassan
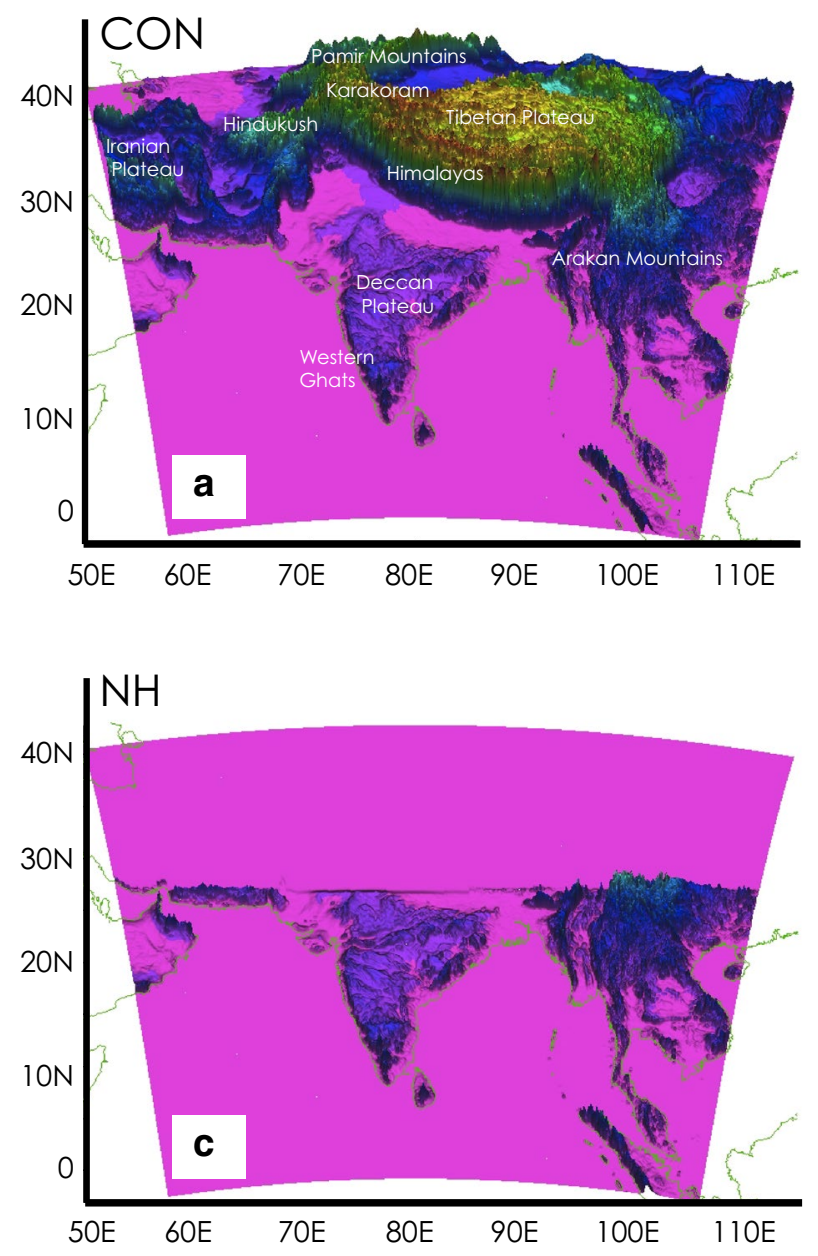

et al. 2015, Huo and Peltier 2020, Karki et al. 2017, and Rana et al. 2020). For this study, the simulation domain is centered at $21^{\circ} \mathrm{N}$ and $80^{\circ} \mathrm{E}$ and consists of 660 points along the longitude and 540 points along the latitude. Grid points are separated by $9 \mathrm{~km}$ horizontally and distributed through 27 vertical levels in the atmosphere. The lateral and lower boundary forcing are provided every $6 \mathrm{~h}$ using the National Center for Environmental Prediction final reanalysis operational global analysis data, which is available at $1^{\circ}$ by $1^{\circ}$ grid (https://rda.ucar.edu/datasets/ds083.2/). The WRF model configuration includes Grell-Devenyi ensemble scheme (Grell and Dvénéyi 2002) for the convective, Lin et al. (1983) for the microphysics and Yonsei University scheme (Hong 2010) for the planetary boundary layer parameterizations. Longwave and shortwave radiations are
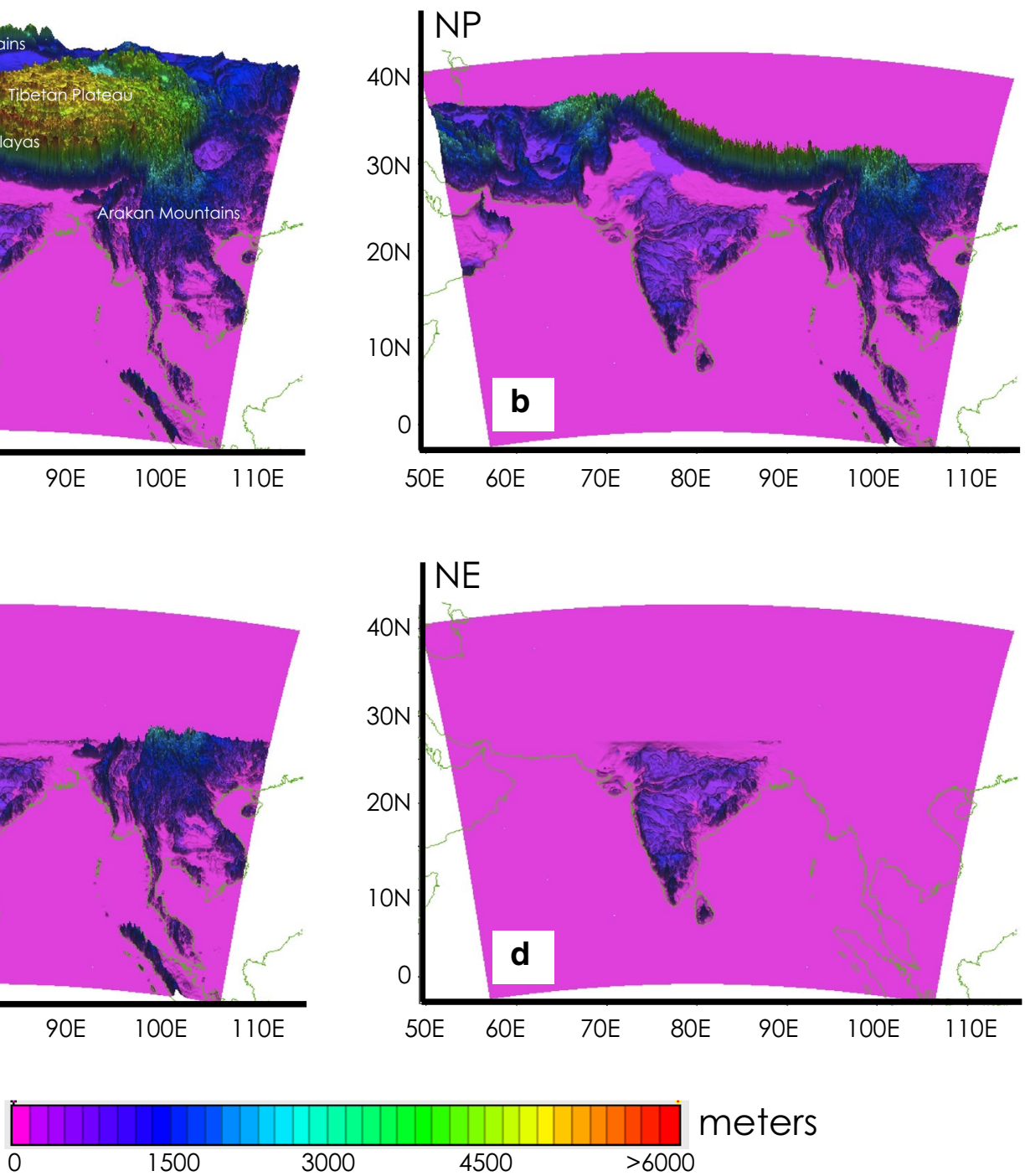

Fig. 1 Elevated surfaces (m) in various experiments: a all elevated surfaces (CON), b no Tibetan Plateau (NP), c no Himalayas, Karakoram and Hindukush (NH), and $\mathbf{d}$ no mountains east of $90^{\circ} \mathrm{E}$ and west of $70^{\circ} \mathrm{E}(\mathrm{NE})$ 
parameterized using the CAM scheme (Collins et al. 2004). For land surface physics, we make use of Noah land surface model (Ek et al. 2003) that has full representation of complex land surface processes and provides sensible and latent heat fluxes as lower boundary condition for the vertical transport in the planetary boundary layer in addition to other time-dependent snow and soil variables. For comparison, we make use of Tropical Rainfall Measuring Mission (TRMM) 3B42 product (Huffman and Bolvin 2015) at $0.25^{\circ}$ grid (https://gpm.nasa.gov/data/directory), CHIRPS data (Funk et al. 2015) (https://www.chc.ucsb.edu/data/chirps) at $0.05^{\circ}$ grid, APHRODITE data (Yatagai et al. 2012) (https://www. chikyu.ac.jp/precip/english/) at $0.25^{\circ}$ grid and TerraClimate data (Abatzoglou et al. 2018) (http://www.climatologylab. org/terraclimate.html) at $\sim 4 \mathrm{~km}$ grid. These comparisons between the observed and simulated precipitation have been shown at their respective grids.

\subsection{Experiments}

We perform five experiments, each covering from May 15 to October 1 for years 2004-2008. All experiments use identical boundary forcing and model parameterizations, but they differ in terms of topographic representation within the domain. The details of topographic representation in each experiment are as following:

1. Reference experiment (CON) This experiment makes use of original topography and serves as a reference to understand the influence of topographic modifications in other experiments (Fig. 1a).

2. No Tibetan Plateau (NP) This is an experiment where the TP is fully removed from the simulation domain (Fig. 1b). The topographic modification follows an approach similar to that in Boos and Kuang (2010). Between $75^{\circ}$ and $100^{\circ} \mathrm{E}$, north of the point at which elevations reaches two-thirds of their maximum at that latitude, the topography is modified by setting surface elevations equal to zero. Similarly, the topography west of $75^{\circ} \mathrm{E}$ is modified by adjusting surface elevations to zero beyond $36^{\circ} \mathrm{N}$ and the topography east of $100^{\circ} \mathrm{E}$ is modified by adjusting surface elevations to zero beyond $29^{\circ} \mathrm{N}$. To avoid erroneous simulation errors and computational instability, which can occur at the sharp edges of modified topography, modifications are carried out gradually in ten steps from maximum to zero.

3. No Himalayas, Karakoram and Hindukush (HKH) mountains (NH) This is an experiment where, in addition to the TP, the Himalayan mountains, and the mountain ranges in the west, including Karakoram and Hindukush are removed (Fig. 1c). This topographic modification is achieved by setting surface elevations at each longitude north of $26.5^{\circ} \mathrm{N}$ equal to zero.
4. No Mountains east of $90^{\circ} \mathrm{E}$ and west of $70^{\circ} \mathrm{E}(\mathrm{NE})$ This experiment removes all the mountains east of the $90^{\circ} \mathrm{E}$ over Myanmar and northeast India by setting surface elevation to zero. It also removes remaining elevated surfaces west of $70^{\circ} \mathrm{E}$ (Fig. 1d).

5. No Topography (NT) This is the final experiment that removes all the remaining elevated surfaces over India, including the Deccan Plateaus and the Western Ghats.

\subsection{Analyses}

We calculate the meridional tropospheric temperature difference (MTD, index for meridional differential heating in the troposphere) of the seasonal mean (June-September) temperature between the upper tropospheric layers $\left(200-500 \mathrm{mb}\right.$ ) at $30^{\circ} \mathrm{N}$ and $5^{\circ} \mathrm{N}$, averaged over the zonal belt between $50^{\circ}$ and $85^{\circ} \mathrm{E}$ (Li and Yanai 1996). We define the vertical shear of zonal winds (U-Shear) as the difference of the seasonal mean of zonal winds between 200 and $850 \mathrm{mb}$ averaged over $50^{\circ}-90^{\circ} \mathrm{E}$ and $0^{\circ}-15^{\circ} \mathrm{N}$ (Webster and Yang 1992; Webster et al. 1998). Moreover, we calculate the equivalent potential temperature $\left(\theta_{\mathrm{e}}\right)$ using a built-in function in the NCAR Command Language (https://www. ncl.ucar.edu/). The results presented as a latitudinal crosssection represent an averaged over $70^{\circ}-90^{\circ} \mathrm{E}$. In addition, we reproduce supporting analyses based on the findings of a previous study (Ashfaq et al. 2017), including apparent heat source $\left(Q_{1}\right)$, surface latent and sensible heat fluxes in the NCEP/NCAR reanalysis, monsoon dynamics (MTD, U-Shear) and summer precipitation in selected GCMs from the 5th phase of Coupled Model Intercomparison Project (CMIP5). The $Q_{1}$ has been calculated at daily timescale for the upper tropospheric layers (200-500 mb) using atmospheric winds, vertical pressure velocity and temperature, following the methodology described in Yanai et al. (1973).

\section{Results and Discussion}

\subsection{Topographic Influence on Precipitation Distribution}

For sensitivity analyses, it is imperative to have a numerical model configuration that can provide unparalleled accuracy in the precipitation distribution over the region of interest to minimize the influence of the model's internal biases on the anomalies introduced by the topographic modifications. To this end, we note that the spatial distribution of summer precipitation in the $C O N$ experiment displays high correspondence with the observations over the South Asian land regions (Fig. 2a-e). Few noticeable exceptions exist over the eastern land regions (Eastern Ghats) where simulated precipitation exhibits 
Fig. 2 Average summer (JuneSeptember) monsoon precipitation $(\mathrm{mm} /$ day) in the a WRF model CON simulations, and b TRMM, c APHRODITE, d CHIRPS, e TerraClimate observations during 2004-2008. All datasets have been shown at their native grid
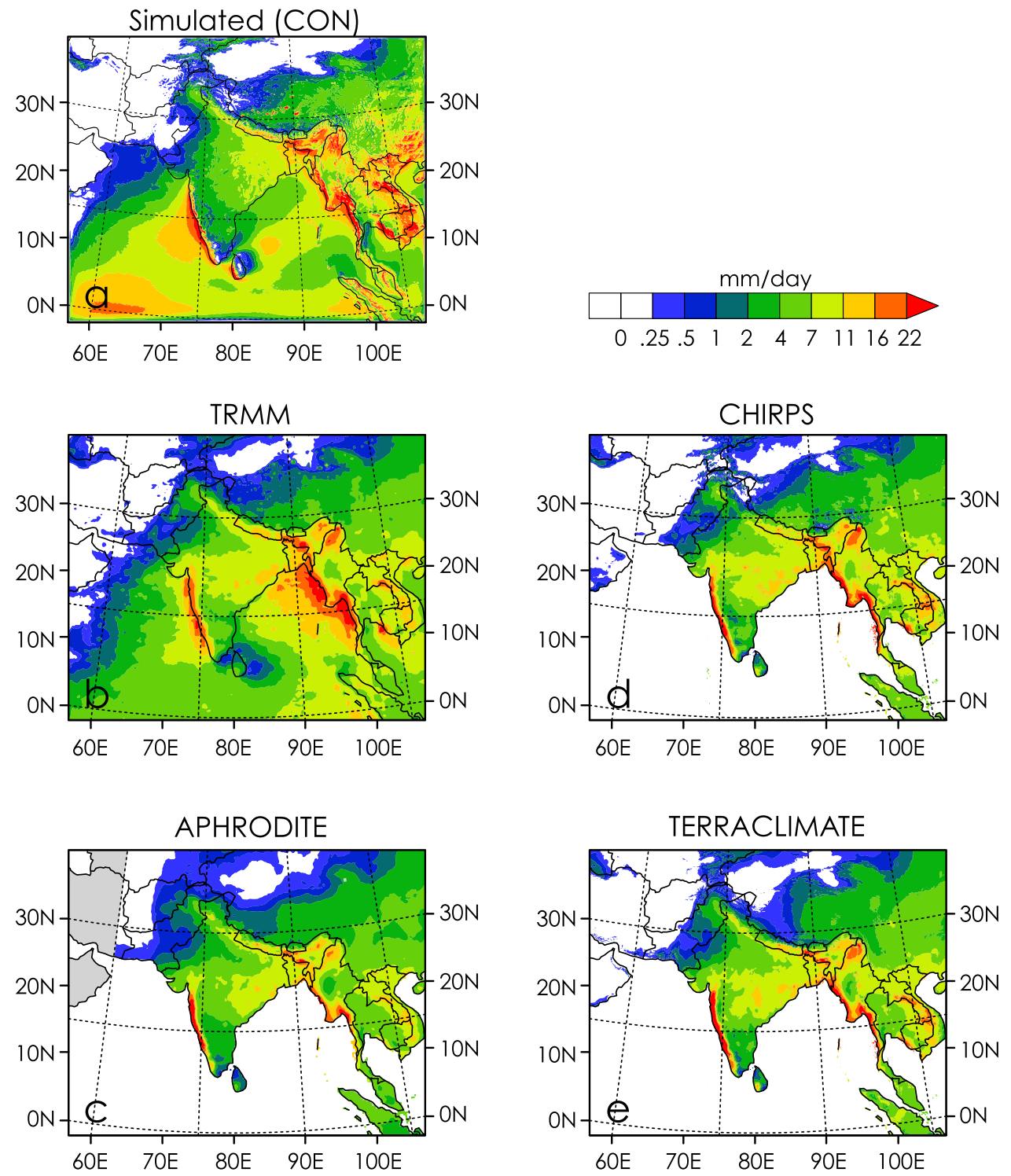

overestimation (underestimation) bias. Some disagreements in the magnitudes over the precipitation hot spots can be due to the resolution differences between the observations and the model simulations, as, ironically, observations underrepresent spatial variability of precipitation despite their higher grid spacing (CHIRPS, TerraClimate), which points to the fact the finer grid spacing does not necessarily represent the resolution of the observations over South Asia. This lack of detail is mainly due to the insufficient density of station observations across the region. The four observations also exhibit noticeable differences in the distribution of precipitation, which highlights observational uncertainty over this region. Apart from that, excessive precipitation bias in the $\mathrm{CON}$ experiment over the Arabian Sea is a common deficiency in numerical models with prescribed sea surface temperatures (e.g., Cavazos et al. 2020 and Yang et al. 2019).
The SASM exhibits distinct topographically driven precipitation maxima along the mountain ranges that separate coastal plains from the inland basins in the southwestern India and Myanmar (Western Ghats and Arakan mountains), and along the Himalayas, in addition to notable rain-shadow region over the Eastern Ghats in southern India. The northern stretch of precipitation moves along the Himalayas from the Bay of Bengal to north-central Pakistan in the westnorthwest South Asia. Moreover, precipitation exhibits a progressive east-west contrast with higher magnitudes over Bangladesh in the east and lower magnitudes over Pakistan in the western Balochistan province.

The elimination of the TP and Pamir mountains in the NP experiment removes the bulk of elevated terrain, leaving South Asia with a thin belt of the Himalayas in the north and Karakoram and Hindukush mountain ranges in the west-northwest, which separates the moist and 
warm South Asia from the dry and cold Eurasian region in the north and arid central-southwest Asia in the west (Fig. 1b). Such a modification in topography weakens the northern branch of SASM in the NP experiment with stronger decreases over Bangladesh and northeastern India (Fig. 3a). The suppressive impact from the removal of TP on the northern branch of SASM progressively diminishes from northeast to northwest. Moreover, the below normal precipitation anomaly in the north-northeast is compensated by an excessive rainfall anomaly over southsouthwestern India.

The additional removal of the HKH mountain ranges in the NH experiment (see Fig. 1c) reduces the excessive precipitation anomaly over south-southwestern India (below $20^{\circ}$ E) that appeared in the NP experiment (see Fig. 3b). Alternatively, positive precipitation anomaly appears over the terrestrial region in the northeast ( east of $90^{\circ} \mathrm{E}$ ), covering northeast India, Bangladesh and Myanmar (Fig. 3e).

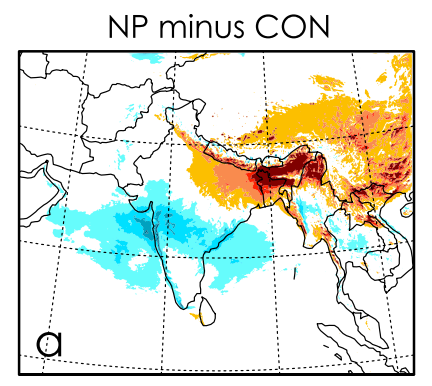

$\mathrm{NH}$ minus $\mathrm{CON}$

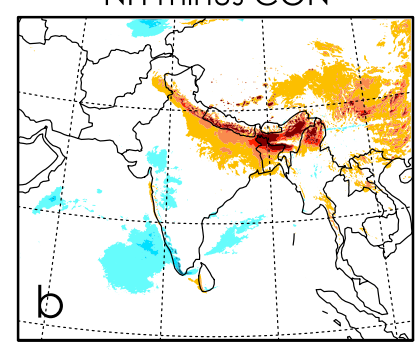

NE minus CON
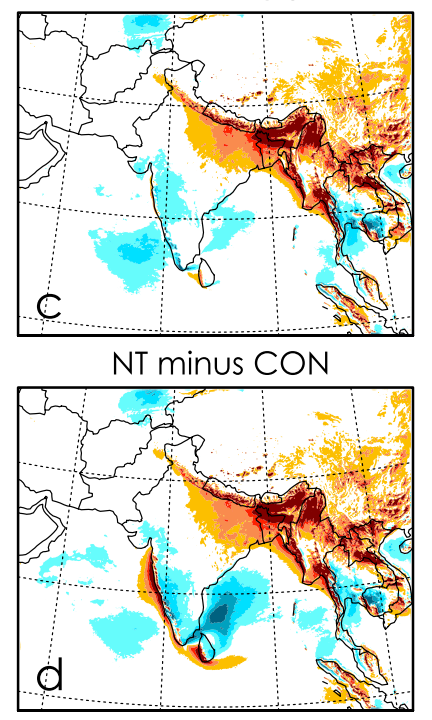
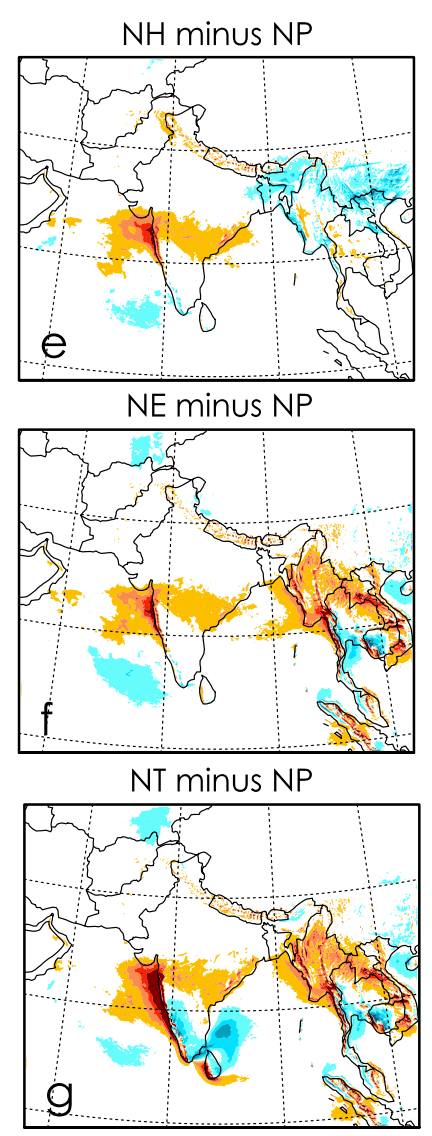

\section{Precipitation changes due to topographic modifications}

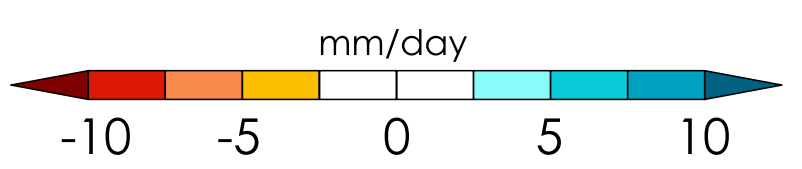

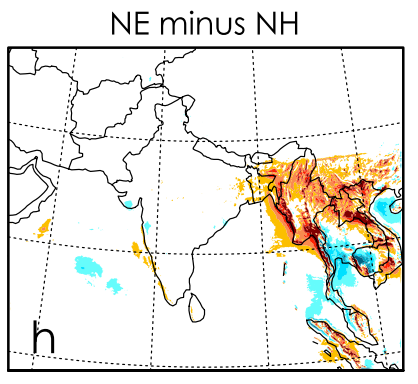
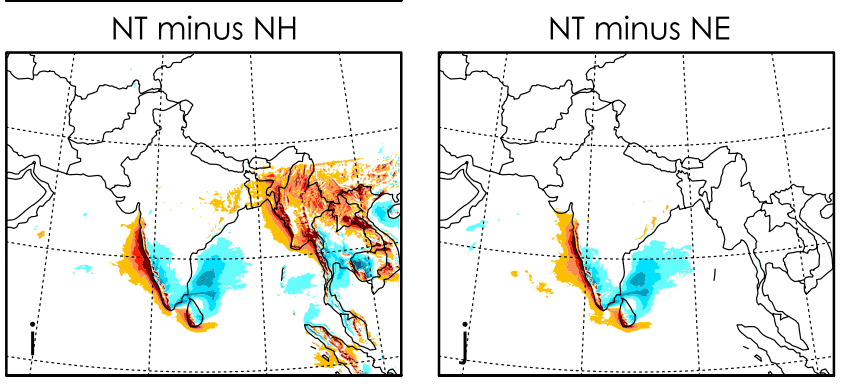

Fig. 3 Changes $(\mathrm{mm} /$ day) in summer precipitation in various modified topography experiments: a NP minus CON, b NH minus CON, c NE minus CON, $\mathbf{d}$ NT minus CON, e NH minus NP, f NE minus NP, g NT minus NP, h NE minus NH, i NT minus NH, and $\mathbf{j}$ NT minus
NE. The diagonal (a, e, $\mathbf{h}$ and $\mathbf{j}$ ) represents precipitation change contributed by each topographic modification while the first column (a, b, $\mathbf{c}$ and $\mathbf{d}$ ) represents progressive changes after each modification 
The nonexistence of orographic lift in the $\mathrm{NH}$ experiment further reduces topographically forced precipitation over the Himalayan region. However, compared to the NP experiment, northern branch of summer monsoon is relatively less weak in the NH experiment (Fig. 3a, b). The NE experiment $\left(\mathrm{NP}+\mathrm{NH}+\right.$ no elevated surface east of $90^{\circ} \mathrm{E}$; Fig. 1d) not only eliminates the excessive precipitation of the $\mathrm{NH}$ experiment (east of $90^{\circ} \mathrm{E}$ ), it also substantially reduces the monsoon precipitation over those regions that is present in the CON experiment (Fig. 3c, f, h). The NE experiment does not have any noticeable influence on the precipitation distribution over the rest of South Asia. The final experiment with no topography (NT), which removes remaining elevated surfaces over India, reduces the orographically driven precipitation over the Western Ghats. Moreover, in the absence of the rain-shadow effect, precipitation over the Eastern Ghats region increases (Fig. 3j).

\subsection{Dynamic and Thermodynamic Drivers of Changes in Precipitation}

There is a need to establish a clear picture of the background state over South Asia during summer season to fully understand how various topographic modifications in our experiments induce changes in the regional dynamic and thermodynamic drivers of SASM and cause anomalies in the rainy season precipitation. On average, monsoon circulations over South Asia exhibit many fundamental characteristics, including a westerly jet over the Arabian Sea along with a southwesterly flow over the Bay of Bengal in the lower troposphere $(\sim 850 \mathrm{mb})$ and an anticyclonic circulation centered around the Tibetan and Iranian Plateaus along with a tropical easterly jet in the upper troposphere $(\sim 200 \mathrm{mb})$. There exists a combination of land-sea and north-south tropospheric thermal contrast on the surface and in the atmosphere, respectively, that overturns the pre-monsoon strong atmospheric subsidence and helps transitioning of the region into a deep convective state (e.g., Ashfaq et al. 2017, Li and Yanai 1996, and Webster et al. 1998). However, it is important to note that while land-sea thermal contrast peaks in May, just before the onset of monsoon season over South Asian land, meridional tropospheric thermal contrast reaches its maximum in July when the rainy season is at its peak. The combination of land and tropospheric warming over South Asia is reflective of the development of sensible heatingdriven heat lows on the surface and precipitation-induced latent heating in the upper atmosphere (Ashfaq et al. 2017). As previously noted, the land in South Asia is the warmest just before the monsoon onset, therefore, it is reasonable to assume that precipitation-induced tropospheric latent heating increasingly becomes the key driver of monsoon progression over land. In other words, precipitation begets more widespread precipitation as it strengthens differential heating gradient in the troposphere. This viewpoint is supported by evidence in both the observation and the model simulations. For instance, atmospheric latent heating-driven tropospheric warming is manifested in the record high MTD over South Asia in June 2013 when Uttarakhand-a northern state of India in the Himalayas-experienced very early monsoon onset and devastating floods due to excessive precipitation (Singh et al. 2014). Similarly, studies based on the analyses of GCMs from the 5th phase of coupled models intercomparison project (CMIP5) have demonstrated a relationship between the amount of simulated precipitation over South Asian north and the strength of MTD (Ashfaq et al. 2017; Rastogi et al. 2018). We will come back to this point again later in the proceeding discussion.

It is important to note that MTD remains negative in all months in a given year except during summer season. Before the onset of rainy season in South Asia, rate of tropospheric warming in the north exceeds than that in the south due to pre-monsoon precipitation (Ashfaq et al. 2017, 2020). As a result, the difference between north and south starts diminishing. By the earliest onset of the rainy season over Kerala in the south and the Bay of Bengal in the northeast, magnitude of tropospheric temperatures in the north exceed that in the south, causing a reversal in the gradient-a monsoon feature that lasts until the end of the summer season. The strongest positive magnitude of this gradient (north warmer than south) coincides with the peak of the rainy season. Since the differential heating gradient again becomes negative at the end of the monsoon season, the seasonal progression and retrieval of SASM can be marked by the seasonal march of this meridional differential heating. The differential warming of the atmosphere between land and ocean regions over South Asia regulates the development of vertical wind shears, such as U-Shear (index for the vertical shear of zonal winds; see Methods) that remains stronger than $20 \mathrm{~m} / \mathrm{s}$ throughout the summer season (Ashfaq et al. 2009; Goswami et al. 1999; Webster et al. 1998; Webster and Yang 1992). The strength of U-Shear has been shown to have indirect association with the strength of MTD over South Asia (Ashfaq et al. 2017).

Given a direct linkage between SASM and meridional differential heating in the troposphere, changes in the characteristics of MTD can be a key in determining the causes of anomalies in various modified topography experiments. For instance, Ashfaq et al. (2017) noted that general circulation models with weak MTD tend to exhibit delayed onset, southward monsoon trough, and weaker-than-normal precipitation over South Asian north-northwest. Similarly, Rastogi et al. (2018) showed that models with such a weak MTD bias exhibit westward monsoon depressions trajectories compared to the north-northwestward path taken on average by monsoon depressions in the observations. Boos and Hurley (2013) noted that lower-than-observed tropospheric 
heating in the CMIP5 GCMs could be due to overly smooth topography that allowed the entertainment of dry air from the arid West Asia. Nonetheless, it is the strength of moist convection in the north-northwest South Asia that eventually determines the magnitude of tropospheric warming (e.g., Singh et al., 2014). To this end, there are other factors, such as the strength of upper and/or lower level jets and anomalies in the strength and/or the positioning of the upper level anticyclone, that can also exert influence on the distribution of precipitation in South Asia. For instance, weaker-thannormal westerly jet limits the lower level moisture transport (e.g., Mei et al. 2015), while weakening of the monsoon circulations in the lower and upper troposphere weakens the background relative vorticity that has an impact on the frequency of low-pressure systems over South Asia (Rastogi et al. 2018; Rao et al. 2004). Similarly, shift in the anticyclonic circulation in the upper troposphere is known to have influence on the inter-annual variability of monsoon precipitation (Wei et al. 2015; Ashfaq et al. 2009). The relationship between the strength of upper level easterlies and the tropospheric differential heating has also been well established (Abish et al. 2013).

With this background in mind, we compare MTD and U-Shear in the CON and modified topography experiments. The MTD and U-Shear in the CON experiment provide a graphical illustration of their characteristics described in the preceding paragraph (Fig. 4). All modified topography experiments exhibit weaker MTD right from the beginning of the summer monsoon season (June 1). It should be noted that pre-monsoon precipitation is mostly convective, which is distributed along the slopes of HKH (Ashfaq et al., 2017), in contrast to the monsoon season where precipitation is widespread and the fraction of stratiform precipitation also increases due to the presence of organized precipitation systems (Ashfaq et al., 2020; Schumacher and Houze,
2003). An obvious impact of the removal of the TP and other elevated surfaces is the entertainment of dry and cold air, which makes conditions inefficient for moist convection. Therefore, weaker MTD at the start of monsoon season (Fig. 4a) is likely a result of reduced moist convection right from the beginning (May 15) of the modified topography experiments. The impacts of dry entrainment have been discussed in more detail later in this section. During the summer season, the reduction of precipitation in the northern branch of summer monsoon in the NP experiment substantially limits the precipitation-induced tropospheric warming in the north, resulting in the weakening of MTD by several degrees throughout the summer months. Interestingly, further removal of other topographic components of South Asian terrain does not have any noticeable impact on the strength of MTD beyond what is already witnessed in the NP experiment. These negligible influences of the additional modifications are not surprising given that it is the location of precipitation anomalies that dictates how temperature difference between north and south is shaped in each experiment. The bulk of negative precipitation anomaly in the northern South Asia comes from the removal of TP (NP experiment) and further topography modifications mostly reduce precipitation in the east and/or south of the domain. In fact, it is the contrast in the precipitation anomalies south of $20^{\circ} \mathrm{N}$ between the NP and other experiments what apparently drivers their MTD differences at intra-seasonal timescales (Figs. 3, 4a). A combination of enhanced precipitation in the south (below $20^{\circ} \mathrm{N}$ ) and reduced precipitation in the north leads to the strongest decrease of MTD in the NP experiments, which is in contrast to other experiments that remove excess precipitation from the south, and hence their MTD magnitudes are relatively stronger than those in the NP experiment during most of the mid to late season. As previously noted, after the monsoon onset over the southern
Fig. 4 a Meridional tropospheric temperature difference index (MTD; K) and b vertical shear of zonal winds index (U-Shear, $\mathrm{m} / \mathrm{s}$ ) in all experiments
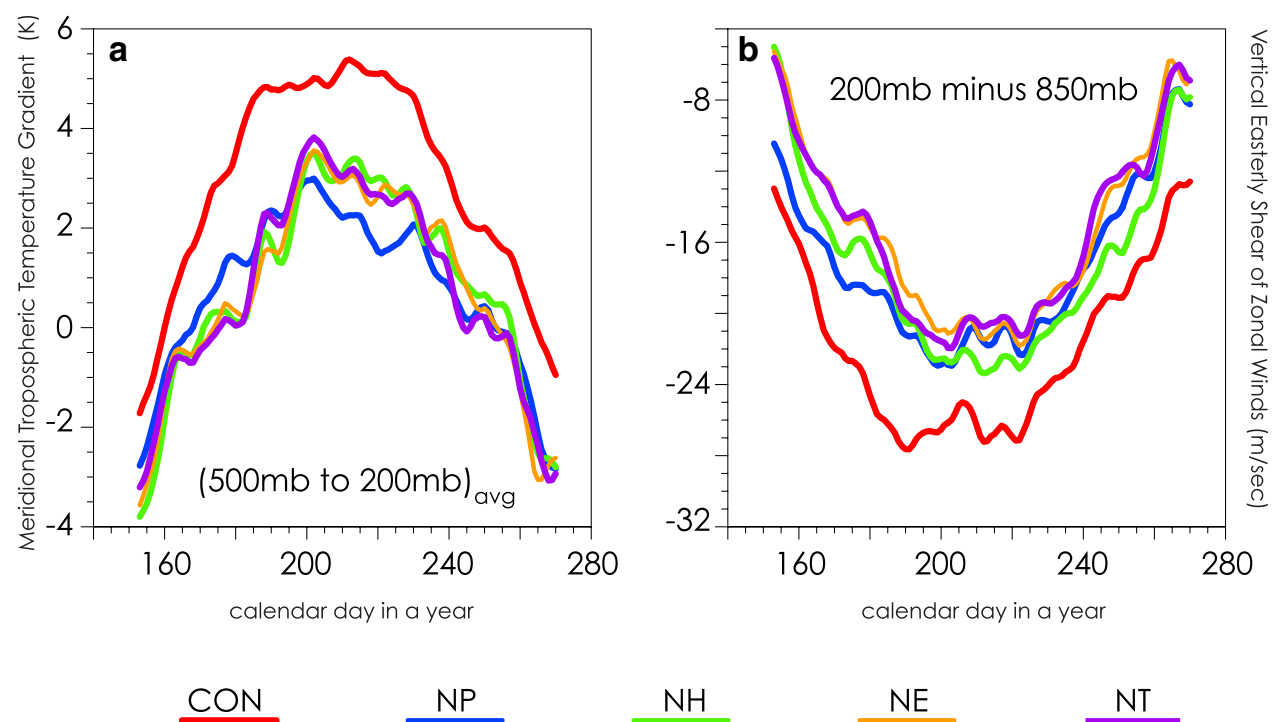

$\mathrm{NH}$ 
and northeastern edges of South Asia, further northwestward progress over land is due to a delicate balance between moist convection and its latent heating-induced tropospheric warming in the atmosphere that strengthens MTD which in turn helps in the progression of monsoon over land. Lack of sufficient precipitation begets more drying through the continuous feedback loop between precipitation and MTD.

Consistent with earlier findings (Ashfaq et al., 2017), the anomalies in U-Shear are in line with the anomalies in MTD as U-Shear exhibits a decrease in all experiments with modified topography (Fig. 4). While the strongest decrease in this case is witnessed in the NT experiment, compared to the NP experiment, we also note a slight recovery in the NH experiment in the latter half of the season. Knowing that anomalies in the strength of vertical shear in the atmosphere depends on the characteristics of circulations anomalies in both the lower and upper troposphere, we also analyze circulation changes at $875 \mathrm{mb}$ and $200 \mathrm{mb}$ in all experiments (Figs. 5, 6). In the lower troposphere, strongest changes are observed in the northern flank of westerlies, which are mostly consistent in all modified topography experiments as onshore flow from the Arabian Sea exhibits a reduction (Fig. 5). Other lower level circulation anomalies vary across different experiments. In the NP experiment, the lower level southwesterly flow through the Bay of Bengal that transports moisture to the northern stretches of South
Fig. 5 Lower level $(875 \mathrm{mb})$ atmospheric circulations (vectors, $\mathrm{m} / \mathrm{s}$ ) and geopotential height (contours, m). a CON, b NP minus CON, c NH minus CON, $\mathbf{d}$ NE minus CON, and $\mathbf{e}$ NT minus CON
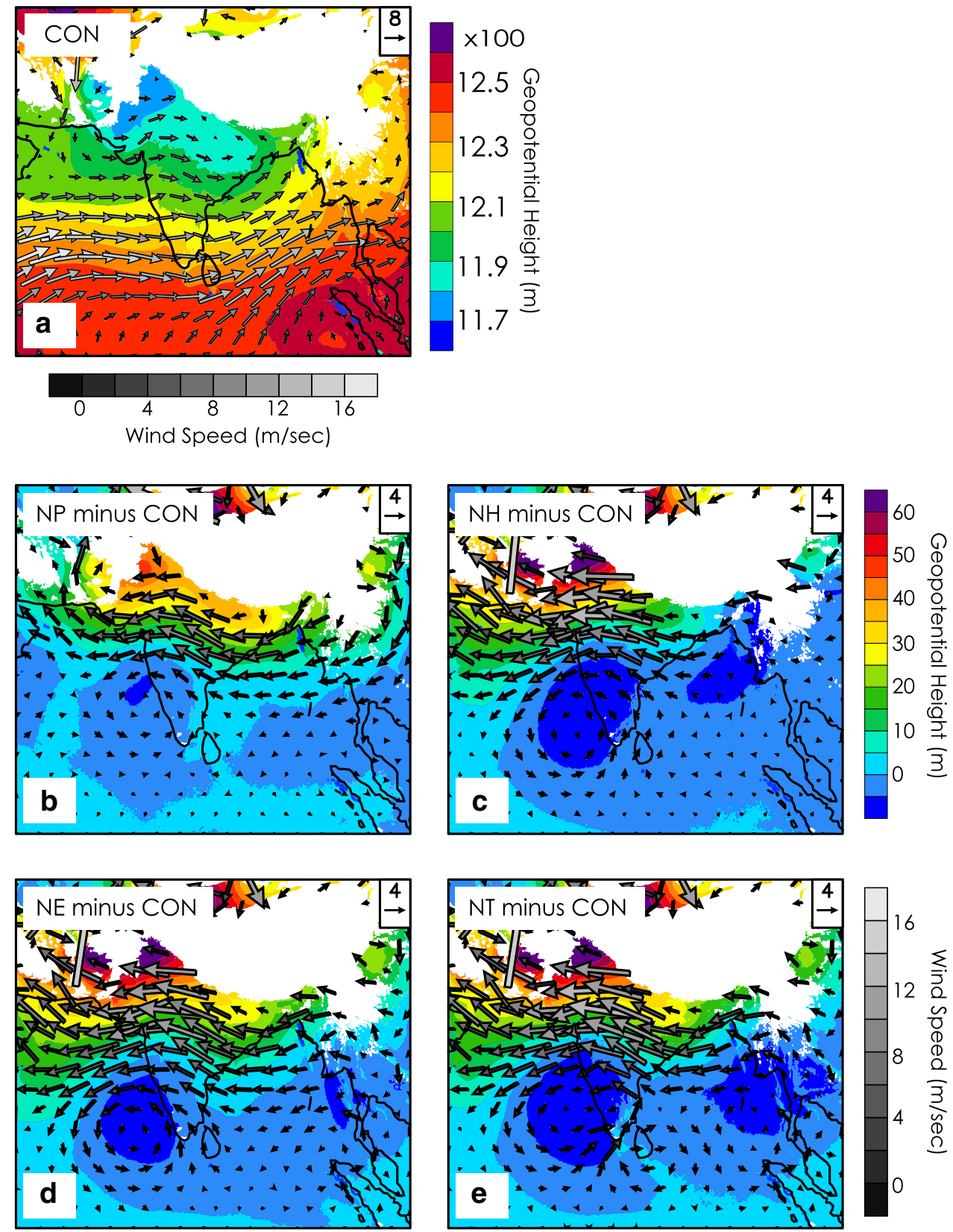
Fig. 6 Upper level (200 mb) atmospheric circulations (vectors, $\mathrm{m} / \mathrm{s}$ ) and geopotential height (contours, m). a CON, b NP minus CON, c NH minus CON, $\mathbf{d}$ NE minus CON, and $\mathbf{e}$ NT minus CON
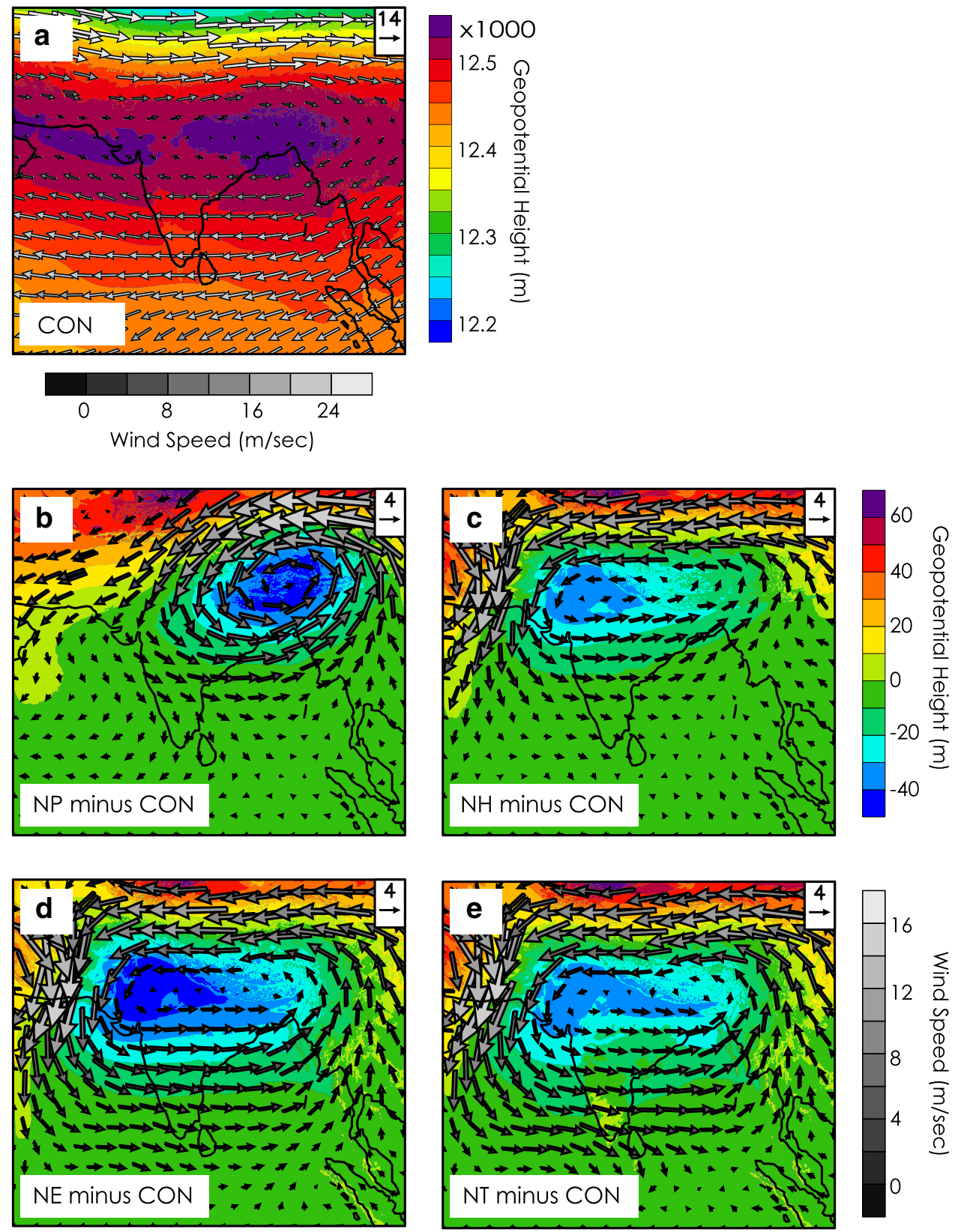

Asia along the Himalayas gets disrupted as an anomalous anticyclonic circulation circumvents the modified topography, allowing dry entertainment from the northeast (Fig. 5b). Due to this anomalous circulation, the strength of onshore flow over Myanmar and Bangladesh is also affected. Alternatively, there is an increase in moisture transport over the south-southwestern India from the Bay of Bengal and from the Arabian Sea as a result of a weak cyclonic anomaly. When the HKH are removed in the NH experiment, it cuts off the circumventing flow from the northeast reducing the dry entrainment in South Asian north. The anomalous moist flow towards southwestern India from the Bay of Bengal also diminishes (Fig. 5c). Similarly, the anomalous offshore flow over Bangladesh and Myanmar in the NP experiment disappears in the $\mathrm{NH}$ experiment. These differences in the lower level circulations response explain why weakening of northern branch of summer monsoon in the $\mathrm{NH}$ experiment is not as robust as it is in the NP experiment (see Fig. 3a, b). Further removal of mountains east of the $90^{\circ} \mathrm{E}$ in the NE experiment again disrupts the onshore flow over Bangladesh and Myanmar and increases the anomalous moist flow over southwestern India through the Bay of Bengal (Fig. 5d). The southwesterly flow from the Bay of Bengal to the northern South Asia also weakens in the absence of mechanical deflection from Arakan mountains (Wu et al., 2014). Apart from that, it does not have any noticeable impact on 
the cyclonic anomaly over the Arabian Sea beyond what is already present in the NH experiment. The most noticeable addition in the anomalous circulation pattern in the final experiment that removes the remaining elevated surfaces (NT) is noticed along the western and eastern Ghats where anomalies favor more (less) onshore flow over the rainshadow (Western Ghats) region (Fig. 5e).

In the upper troposphere $(200 \mathrm{mb})$, circulations exhibit a cyclonic anomaly centered over the northeastern South Asia in the NP experiment, which reflects weakening of the upper level anticyclone and the tropical easterly jet (Fig. 6b). These circulation changes are located over the northeastern region where maximum precipitation reduction is witnessed in this experiment. It is interesting to note that several earlier studies have also suggested the influence of thermal and mechanical forcing from the TP over northeast South Asia, particularly during the onset phase (Park et al., 2012; Wu and Zhang 1998). The strength of cyclonic anomaly over the northeast weakens as it stretches westward over South Asia when the HKH are removed in the NH experiment (Fig. 6c). Further removal of mountains east of $90^{\circ} \mathrm{E}$ in the NE experiment exacerbates the weakening of the tropical easterly jet over the Bay of Bengal and the Arabian Sea (Fig. 6d). Some incremental weakening is also witnessed when remaining topography over India is removed in the NT experiment. Overall, South Asia experiences a progressive weakening of the anticyclonic circulation in the upper troposphere with the gradual removal of elevated surfaces while monsoon trough moves southward due to anomalies in the lower levels.

An analysis of lower level sub-cloud $\theta_{\mathrm{e}}$ has often been used to highlight changes in the thermodynamic structure of boundary layer in the $\mathrm{CON}$ and modified topography experiments (e.g., Boos and Kuang 2010). Higher magnitudes of $\theta_{\mathrm{e}}$ reflect positively buoyant air or convective instability as $\theta_{\mathrm{e}}$ increases with temperature and atmospheric moisture content. We show latitudinal cross-section of $875 \mathrm{mb}$ $\theta_{\mathrm{e}}$ and precipitation averaged between $70^{\circ}-90^{\circ} \mathrm{E}$ to highlight the location of their maxima in various experiments (Fig. 7a). Over South Asia, $\theta_{\mathrm{e}}$ maxima are witnessed south of the TP $\left(25^{\circ}-30^{\circ} \mathrm{N}\right)$, which also coincides with the location of the maximum tropospheric warming and the bulk of domain averaged summer precipitation (Figs. 7b, 8a) in the $C O N$ experiment. As dynamical anomalies induced by the removal of TP limit moisture supply and reduce precipitation over northern latitudes of South Asia, magnitudes of $\theta_{\mathrm{e}}$ substantially drop north of $20^{\circ} \mathrm{N}$, reflecting a non-conducive environment for atmospheric convection. Further removal of other topographic features exacerbates these conditions which results in a southward shift in the monsoon precipitation. As previously noted, a slight recovery of precipitation between $22^{\circ}$ and $26^{\circ} \mathrm{N}$ can also be seen in the $\mathrm{NH}$ experiment, which is also reflected in the higher magnitudes of MTD over the northeastern South Asia and in the slight recovery of the U-Shear in the latter half of the season (Fig. 8c).

\subsection{Is There a Middle Ground in this Debate?}

The hemispheric oscillation of the intertropical convergence zone in search of the thermal equator is fundamentally regulated by the orbiting of Earth around the Sun. While the resulting rapid monsoonal transitions are even witnessed in
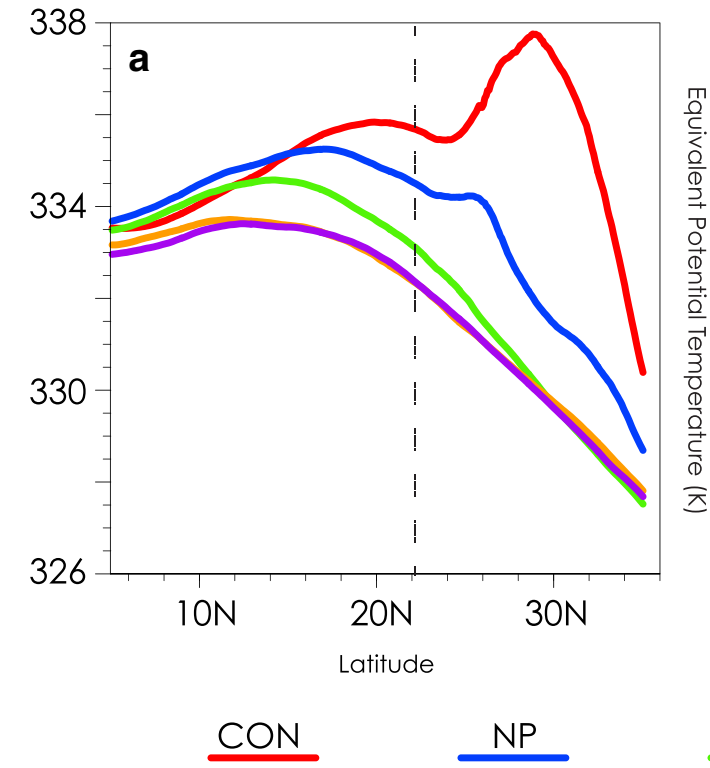

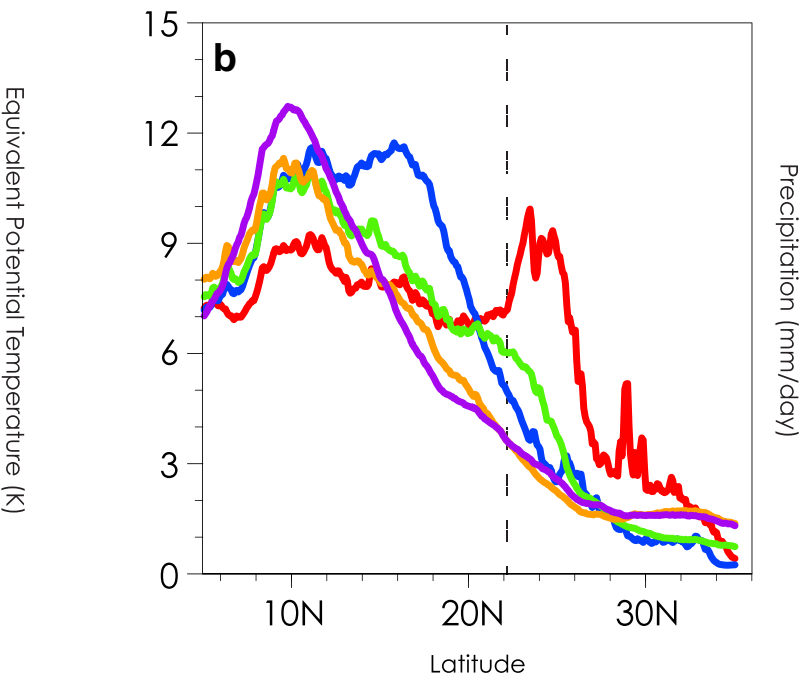

$\mathrm{NH}$

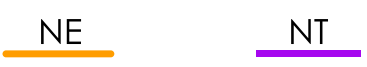

Fig. 7 Zonal average $\left(70^{\circ}-90^{\circ} \mathrm{E}\right)$ a $875 \mathrm{mb}$ equivalent potential temperature $\left(\theta_{\mathrm{e}} ; \mathrm{K}\right)$ and $\mathbf{b}$ precipitation (mm/day) during summer season in all the experiments 
Fig. 8 Average tropospheric temperature $(\mathrm{K})$ between 200 and $500 \mathrm{mb}$ during summer season. a CON, b NP, c NH, d $\mathrm{NE}$, and $\mathbf{e} \mathrm{NT}$

\section{Average Tropospheric Temperature between $200 \mathrm{mb}$ to $500 \mathrm{mb}$}
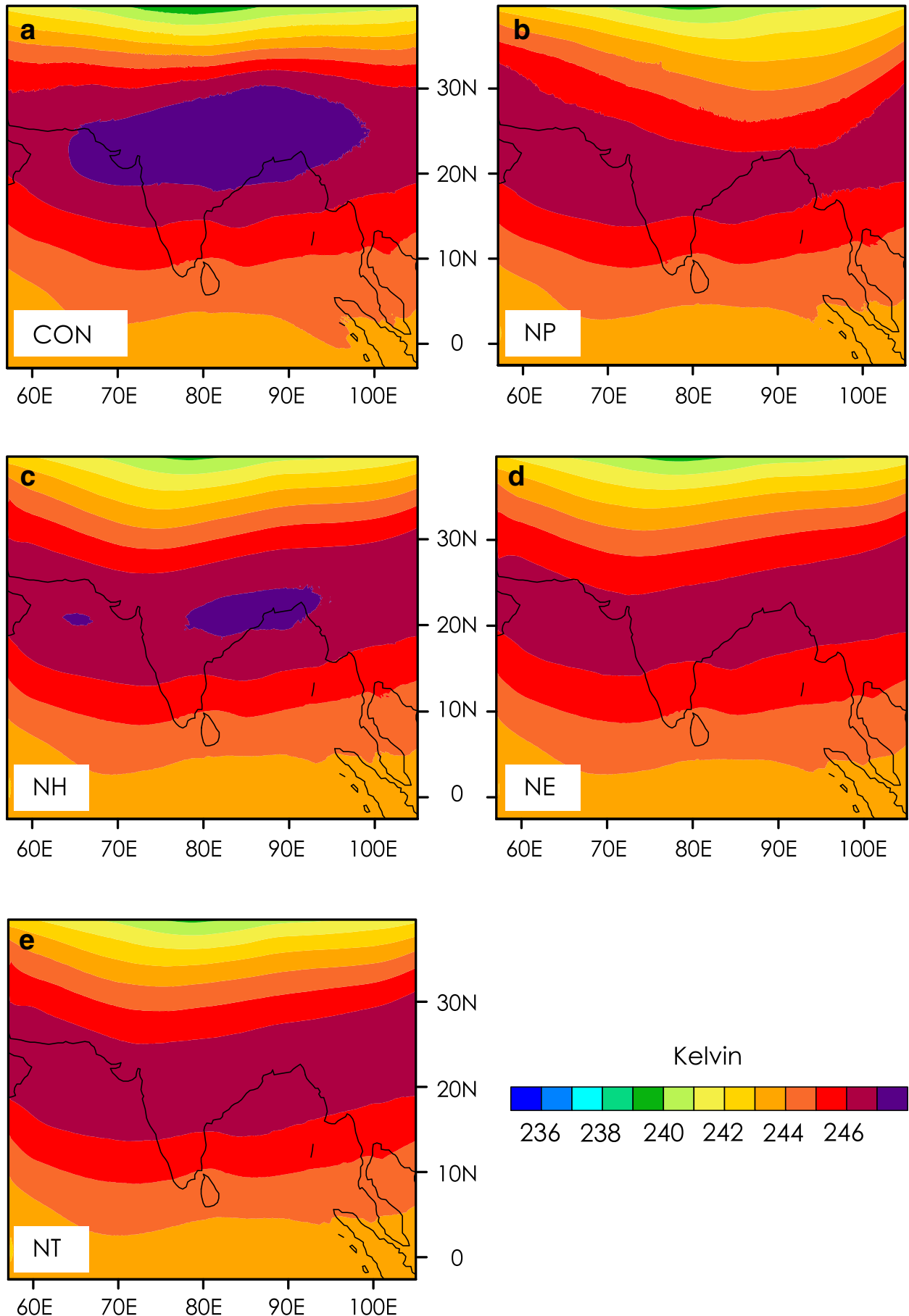

Kelvin

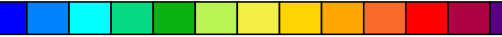

$\begin{array}{llllll}236 & 238 & 240 & 242 & 244 & 246\end{array}$ the aqua planet simulations (Bordoni and Schneider 2008), it is ultimately the shape of the continent/subcontinent, surface heterogeneities, and the characteristics of meridional differential heating that form the distinct characteristics of precipitation distribution over each monsoon region. Numerical modeling studies demonstrate that land-sea thermal contrast is often sufficient for the arrival of monsoon rains over land (e.g., Wu et al. 2012); however, a multitude of factors may determine the extent of subsequent meridional progression. Take an example of West and East African (Australian) monsoons that extend up to $\sim 20^{\circ} \mathrm{N}\left(\sim 20^{\circ} \mathrm{S}\right.$ ) (Ashfaq et al. 2020; Almazroui et al. 2020b) and do not have any elevated surfaces in their north (south). The northward extent of South Asian monsoon is not very different from these monsoons when it is stripped of its elevated surfaces (Figs. 3, 7b). And it is at this point where debate regarding the role of thermal 
and/or mechanical topographic forcing in furthering the north-northwestward progress of monsoon over South Asia heats up. Most of the studies agree that if we only retain the HKH (NP experiment), their topographic insulation is sufficient to generate the northern branch of SASM (e.g., Acosta and Huber, 2020, Boos and Kuang 2010, 2013, Ma et al. 2014, and Wu et al. 2012).

Our results do not necessarily provide contradictory evidence to the findings of previous studies; however, the reduction in the strength of northern branch of South Asian monsoon after the removal of TP (NP) is substantially robust in our experiment than what has been reported earlier. Here, one cannot rule out the possibility that the disagreements in our experiments may partly be due to the differences in our modeling approach. More importantly, we find a progressive weakening of upper level anticyclonic circulation and tropical easterly jet with the gradual removal of elevated surfaces in our experiments. Only exception is in the case of $\mathrm{NH}$ experiment where weakening of the easterly jet over the northeast is slightly reduced (see Fig. 6c), which is consistent with the precipitation response (see Fig. 3e). Overall, these results suggest that monsoon circulations are responsive to changes in both thermal (moist convection) and mechanical forcing. Therefore, regulatory role of elevated surfaces, such as TP, in maintaining the northern branch of SASM cannot be completely ruled out. Beyond this, our experimental framework is rather limited to quantitatively answer the question that whether it is the thermal forcing or the mechanical forcing that regulate topographic influence of remaining elevated surfaces in retaining the weakened northern branch of South Asian monsoon, as it has been addressed in earlier studies (Boos and Kuang 2013; $\mathrm{Wu}$ et al. 2012). However, sensitivity experiments are not always a requirement for such investigations as one can also seek answers to these questions by comparing precipitation biases and their driving mechanisms in a suite of GCMs with similar topographic forcing. Fortunately, in an earlier study (Ashfaq et al. 2017), we performed detailed analyses of CMIP5 GCMs to understand the nature and sources of their precipitation biases over South Asia. We will take few examples from those analyses to aid this discussion.

First, through the analyses of NCEP/NCAR reanalysis, we note that the sensible heating maxima over South Asian north is observed before the onset of monsoon season, in contrast to the latent heat maxima that is observed during the monsoon season (Fig. 9a). These comparisons are shown in three latitudinal bands to reflect the location of their strongest magnitudes. We also note that the annual cycle of surface latent heat flux matches the annual cycle of apparent heat source $\left(Q_{1}\right)$ in the troposphere $(500 \mathrm{mb}$ and $200 \mathrm{mb})$ for all the latitudinal bands, suggesting a dominant role of the moist convection in the tropospheric warming over South Asia (Fig. 9b). Here, surface latent heat flux has been used as a proxy for the moist convection as it directly relates with the evaporation that moistens the atmosphere (Gentine et al. 2013). The maxima for atmospheric diabatic heating and surface heat fluxes lies in the $20^{\circ}-25^{\circ} \mathrm{N}$ latitudinal band, consistent with the maxima of tropospheric temperatures (Figs. 8a, 9b). Second and consistent with the first analysis, we find that models with substantial dry precipitation bias in the northern branch of SASM also exhibit very weak MTD and vice versa. We explain this relationship by considering two extreme cases in the CMIP5 GCM ensemble: Hadley Center and NASA GCMs that represent tail ends of the MTD bias spectrum. HadGEM2-CC and HadGEM2ES are the warmest while GISS-E2-H and GISS-E2-R are the coldest models in terms of MTD bias in the suite of 50 CMIP5 GCMs (Ashfaq et al. 2017) (Fig. 10a). As we have noted earlier that the strength of MTD is a function of precipitation-induced latent heating, particularly over the
Fig. 9 Climatological annual cycle of a surface sensible and latent heat fluxes $\left(\mathrm{W} / \mathrm{m}^{2}\right)$ and b tropospheric apparent heat source $\left(Q_{1} ; \mathrm{K}\right)$ between 200 and $500 \mathrm{mb}$ at various latitudinal bands in NCEP/NCAR reanalysis. The latitudinal bands are used to highlight the location of their maxima. The surface latent heat flux has been used as a proxy for the moist convection as it directly relates with evaporation that moistens the atmosphere. These results have been derived from Ashfaq et al. (2017)

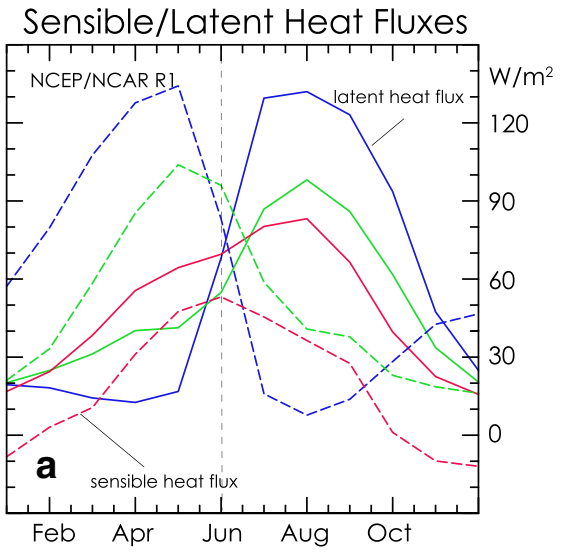

Latitudinal Bands:

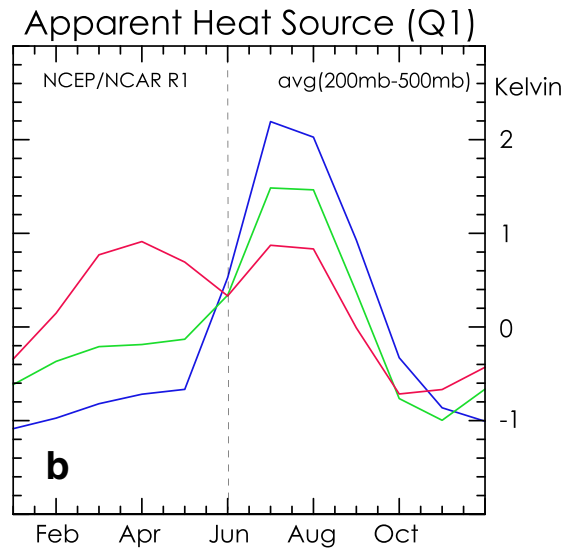

$20^{\circ} \mathrm{N}-25^{\circ} \mathrm{N}, 70^{\circ} \mathrm{E}-90^{\circ} \mathrm{E}$ $25^{\circ} \mathrm{N}-30^{\circ} \mathrm{N}, 70^{\circ} \mathrm{E}-90^{\circ} \mathrm{E}$ $30^{\circ} \mathrm{N}-35^{\circ} \mathrm{N}, 70^{\circ} \mathrm{E}-90^{\circ} \mathrm{E}$ 
Fig. 10 a Climatological meridional tropospheric temperature difference index (MTD; K) and vertical shear of zonal winds index (U-Shear) in selected CMIP5 GCMs and NCEP/ NCAR reanalysis. Climatological summer monsoon precipitation in observations (CRU over land, CPC over ocean) (b), selected CMIP5 GCMs (c-f). These results have been derived from Ashfaq et al. (2017)
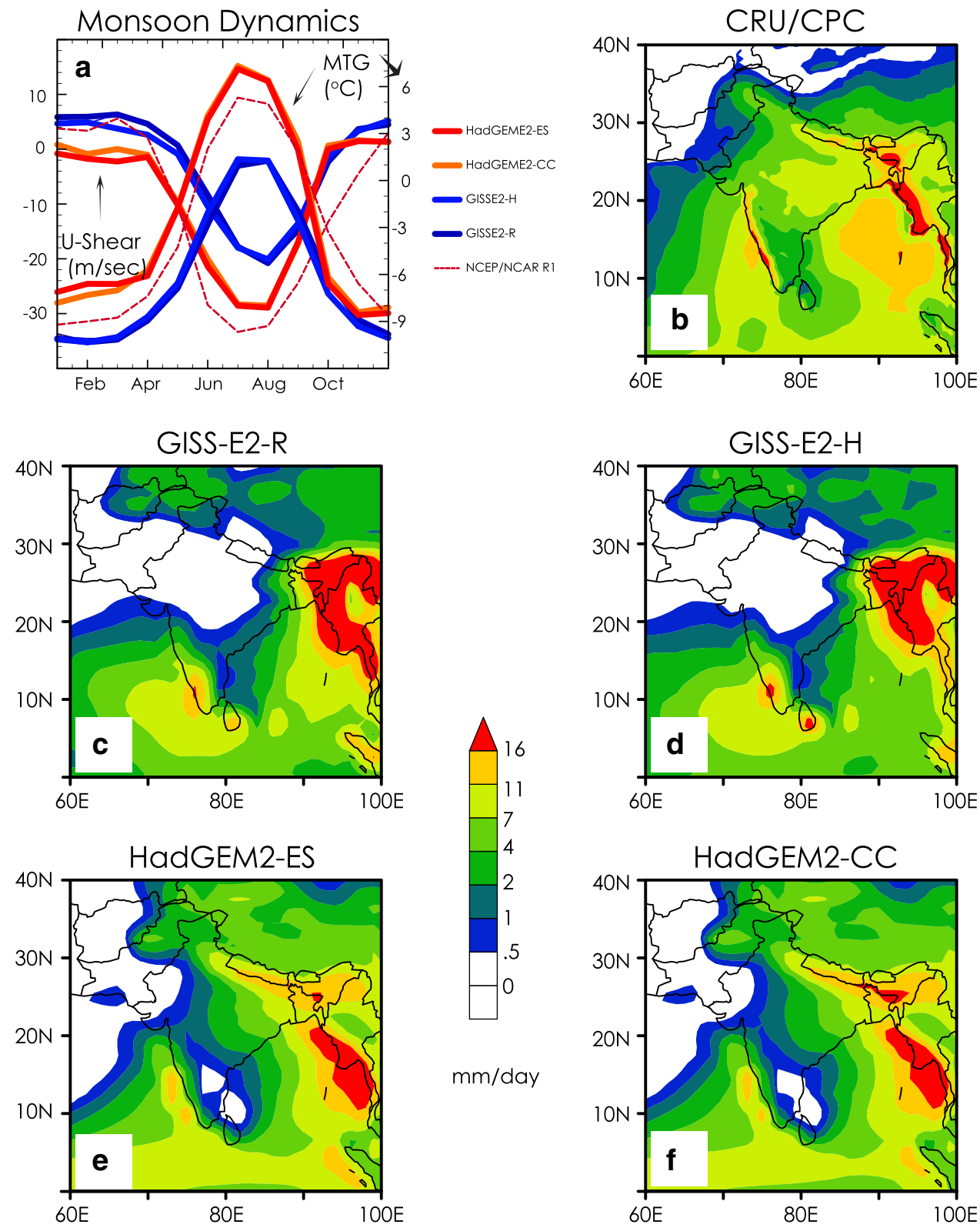

elevated surfaces, models with the weakest MTD exhibit very weak northern branch of SASM while models with the strongest MTD exhibit excessive precipitation over the TP (Fig. 10b-f).

Overall, these comparison of CMIP5 GCMs and regional model experiments with modified topography (this study) suggest that both thermal and mechanical forcing play a role in the normal distribution of precipitation during SASM. Topography prevents dry air entrainment, and indirectly contributes to tropospheric warming through moist orographic convection. Precipitation additionally feedbacks by maintaining the moisture supply through local recycling, which is one of the major sources of moisture particularly during the mature phase of monsoon (Mei et al. 2015). Moreover, the upper level circulations respond to changes in both moist convection and topography. Therefore, a sustained conducive environment for the observed present-day summer precipitation distribution over South Asia delicately hinges on the complementary and interacting thermal and mechanical processes.

Lastly, we would like to caution that design of sensitivity experiments may have an influence on the outcome of such studies over South Asia. For instance, when the Iranian Plateau and mountains in the west are removed and the TP/ Karakoram mountains are retained in one of the experiments considered in Acosta and Huber (2020), it tunnels dry air from the northwest of the domain and leads to substantial drying over the SASM region. Such a forced dry entertainment is absent in their experiment with no elevated surfaces (no topography experiment), which leads to relatively less 
drying. The comparison of these experiments leads one to believe that it is perhaps the presence/absence of the Iranian Plateau that regulates monsoon precipitation over South Asian land by preventing mixing of dry air from West Asia when it is, in fact, the presence/absence of the TP in the two experiments that leads to differences in how the dry air from West Asia interacts with the moist flow over South Asia. Similarly, sensible heating is important for the overturning in the lower troposphere and its forced removal leads to inefficiency of precipitation generating processes and hence to the weakening of tropospheric warming during SASM in a numerical model experiment. Therefore, experiments without sensible heating along the slopes of elevated surfaces (e.g., Wu et al. 2012) can lead to a conclusion that northern branch of South Asia is regulated by the direct influence of sensible heating-driven thermal forcing when it is, in fact, one of the processes that facilitates precipitation and atmospheric diabatic heating through latent heat release. We do, however, note that elevated sensible heating may be important to maintain the strength of upper level anticyclonic circulation and further systematic evaluation is needed in this regard.

\section{Summary}

In this study, we perform a series of high-resolution $(9 \mathrm{~km})$ experiments using the WRF model where South Asia is stripped of its elevated surfaces one by one to understand their individual and collective roles in the maintenance of South Asian summer monsoon and in the distribution of rainy season precipitation. The experiments are based on a one-way nested limited area configuration of the WRF model. While there are clear differences between this study and any of the earlier studies in terms of experimental framework, still, there are some commonalties in the simulated results. Specifically, consistent with earlier studies, we find that precipitation south of $20^{\circ} \mathrm{N}$ is insensitive to thermal and/or mechanical forcing of South Asian mountains in the East, North and West. Apart from that, in some cases, role of mountains is local and limited as a barrier, such as Western Ghats south of $20^{\circ} \mathrm{N}$, while in other cases, elevated surfaces exert their influence both as a barrier/flow regulator and as a modulator of dynamic and thermodynamic characteristics of summer monsoon over South Asia. The moist convection along the slopes of mountain ranges in the South Asian north substantially contributes to the strengthening of MTD and hence in the north-northwestward propagation of SASM. The removal of high plateau regions, the TP in particular, substantially modulates the monsoonal flow in the lower troposphere and the anticyclonic circulation in the upper troposphere to an extent that northern branch of South Asian summer monsoon ceases to exist like the way we know it.
These changes give way to negative precipitation anomalies and eventually to an environment where cycle of feedbacks that runs the very engine of monsoon progression over land becomes inefficient. Nonetheless, we advise caution in the interpretation of these and previously reported results as precipitation responses in these studies are partly sensitive to the choice of models and the design of the experiments.

Acknowledgements We thank four anonymous reviewers for their feedback. This work is supported by the Department of Energy Office (DOE) of Science Biological and Environmental Research as part of Regional and Global Model Analysis program area within the Earth and Environmental Systems Modeling Program, and by the National Climate-Computing Research Center, which is located within the National Center for Computational Sciences at the Oak Ridge National Laboratory and supported under a Strategic Partnership Project, 2316T849-08, between DOE and NOAA. Support for data storage and analysis is provided by the Oak Ridge Leadership Computing Facility at ORNL. The WRF model code is publicly available from https ://www2.mmm.ucar.edu/wrf/users/. The boundary forcing data are available from https://rda.ucar.edu/datasets/ds083.2/. MA would like to thank Danielle Touma and Rui Mei for their help in conducting the experiments. This manuscript has been co-authored by employees of Oak Ridge National Laboratory, managed by UT Battelle, LLC, under contract DE-AC05-00OR22725 with the U.S. Department of Energy. The publisher, by accepting the article for publication, acknowledges that the United States Government retains a non-exclusive, paid-up, irrevocable, world-wide license to publish or reproduce the published form of this manuscript, or allow others to do so, for United States Government purposes. The Department of Energy will provide public access to these results of federally sponsored research in accordance with the DOE Public Access Plan (http://energy.gov/downloads/doepublic-access-plan).

\section{Compliance with Ethical Standards}

Conflict of Interest There is no conflict of interest between the author and the journal.

\section{References}

Abatzoglou JT, Dobrowski SZ, Parks SA, Hegewisch KC (2018) Terraclimate, a high-resolution global dataset of monthly climate and climatic water balance from 1958-2015, Scientific Data

Abish B, Joseph PV, Johannessen OM (2013) Weakening trend of the tropical easterly jet stream of the Boreal Summer Monsoon Season 1950-2009. J Clim 26:9408-9414. https://doi.org/10.1175/ jcli-d-13-00440.1

Acosta RP, Huber M (2020) Competing topographic mechanisms for the summer Indo-Asian monsoon. Geophys Res Lett. https://doi. org/10.1029/2019gl085112

Almazroui M, Saeed S, Islam MN, Ismail M (2020a) Projections of Precipitation and temperature over the South Asian Countries in CMIP6. Earth Syst Environ 4:297-320. https://doi.org/10.1007/ s41748-020-00157-7

Almazroui M, Saeed F, Saeed S, Islam MN et al (2020b) CMIP6 simulated changes of projected temperature and precipitation over Africa CMIP6. Earth Syst Environ 4:455-475. https://doi. org/10.1007/s41748-020-00161-x

Ashfaq M, Shi Y, Tung W, Trapp RJ, Gao X, Pal JS, Diffenbaugh NS (2009) Suppression of south Asian summer monsoon precipitation 
in the 21st century. Geophys Res Lett 36:L01704. https://doi. org/10.1029/2008GL036500

Ashfaq M, Rastogi D, Mei R, Touma D, Leung R (2017) Sources of errors in the simulation of South Asian monsoon in CMIP5 GCMs. Clim Dyn. https://doi.org/10.1007/s00382-016-3337-7

Ashfaq M, Cavazos T, Reboita MS et al (2020) Robust late twenty-first century shift in the regional monsoons in RegCM-CORDEX simulations. Clim Dyn. https://doi.org/10.1007/s00382-020-05306-2

Boos WR, Kuang ZM (2010) Dominant control of the South Asian monsoon by orographic insulation versus plateau heating. Nature 463:218-223

Boos WR, Hurley JV (2013) Thermodynamic bias in the multimodel mean boreal summer monsoon. J Clim 26(7):2279-2287

Boos WR, Kuang ZM (2013) Sensitivity of the South Asian monsoon to elevated and non-elevated heating. Sci Rep 3:1192

Bordoni S, Schneider T (2008) Monsoons as eddy-mediated regime transitions of the tropical overturning circulation. Nat Geosci 1(8):515-519

Cavazos $\mathrm{T}$ et al (2020) Climatic trends and regional climate models intercomparison over the CORDEX-CAM (Central America, Caribbean, and Mexico) domain. Int J Climatol 40(3):1396-1420

Chakraborty A, Nanjundiah RS, Srinivasan J (2006) Theoretical aspects of the onset of Indian summer monsoon from perturbed orography simulations in a GCM. Ann Geophys 24:2075-2089. https://doi.org/10.5194/angeo-24-2075-2006

Chen GSS, Liu Z, Kutzbach JE (2014) Reexamining the barrier effect of the Tibetan Plateau on the South Asian summer monsoon. Clim Past 10(1974):1269-1275

Collins WD, Rasch PJ, Boville BA, Hack JJ, McCaa JR, Williamson DL, Kiehl JT, Briegleb B, Bitz C, Lin S-J, Zhang M, Dai Y (2004) Description of the NCAR Community Atmosphere Model (CAM3). In: Technical Report NCAR/TN464+STR, National Center for Atmospheric Research, Boulder, Colorado 80307-3000, p 226

Devanand A, Huang M, Ashfaq M, Barik B, Ghosh S (2019) Choice of Irrigation Water Management Practice Affects Indian Summer Monsoon Rainfall and Its Extremes. Geophys Res Lett. https:// doi.org/10.1029/2019GL083875

Ek MB, Mitchell KE, Lin Y, Rogers E, Grummann P, Koren V, Gayno G, Tarpley JD (2003) Implementation of Noah land surface model advances in the National Centers for Environmental Prediction operational Mesoscale Eta Model. J Geophys Res 108:8851. https ://doi.org/10.1029/2002JD003296

Fu C, Fletcher JO (1985) The relationship between tibet-tropical ocean thermal contrast and interannual variability of indian monsoon rainfall. J Clim Appl Meteorol 24:841-847

Funk C et al (2015) The climate hazards infrared precipitation with stations-a new environmental record for monitoring extremes. Sci Data 2:150066

Gentine P, Holtslag AAM, D'Andrea F, Ek M (2013) Surface and atmospheric controls on the onset of moist convection over land. J Hydrometeorol 14:1443-1462

Giorgi F (2019) Thirty years of regional climate modeling: where are we and where are we going next? J Geophys Res Atmos 124:5696-5723

Goswami BN et al (1999) A broad-scale circulation index for the interannual variability of the Indian summer monsoon. Q J R Meteorol Soc 125:611-633

Grell GA, Dvénéyi D (2002) A generalized approach to parameterizing convection combining ensemble and data assimilation techniques. Geophys Res Lett 29:38-41

Hahn DG, Manabe S (1975) The role of mountains in the south Asian monsoon circulation. J Atmos Sci 32(8):1515-1541. https://doi.org/10.1175/1520-0469(1975)032\%3c1515:TROMI $\mathrm{T} \% 3 \mathrm{e} 2.0 . \mathrm{CO} ; 2$
Hassan M, Du P, Jia S, Iqbal W, Mahmood R, Ba W (2015) An assessment of the South Asian summer monsoon variability for present and future climatologies using a high resolution regional climate model (RegCM4.3) under the AR5 scenarios. Atmosphere 6:1833-1857. https://doi.org/10.3390/atmos6111833

He B, Liu Y, Wu G, Wang Z, Bao Q (2018) The role of air-sea interactions in regulating the thermal effect of the Tibetan-Iranian Plateau on the Asian summer monsoon. Clim Dyn 52(7-8):42274245. https://doi.org/10.1007/s00382-018-4377-y

Hong SY (2010) A new stable boundary layer mixing scheme and its impact on the simulated East Asian summer monsoon. Q J R Meteorol Soc 136(651):1481-1496. https://doi.org/10.1002/ Qj.665

Huffman GJ, Bolvin D (2015) TRMM and other data precipitation data set documentation. NASA TRMM Doc., p 44, ftp://preci p.gsfc.nasa.gov/pub/trmmdocs/3B42_3B43_doc.pdf. Accessed Nov 2020

Huo Y, Peltier W (2020) Dynamically downscaled climate change projections for the South Asian monsoon: mean and extreme precipitation changes and physics parameterization impacts. J Clim 33(6):2311-2331. https://doi.org/10.1175/JCLI-D-19-0268.1

Karki R, Hasson S, Gerlitz L, Schickhoff U, Scholten T, Böhner J (2017) Quantifying the added value of convection-permitting climate simulations in complex terrain: a systematic evaluation of WRF over the Himalayas. Earth Syst Dyn 8:507-528. https://doi. org/10.5194/esd-8-507-2017

Karmacharya J, Jones R, Moufouma-Okia W, New M (2017) Evaluation of the added value of a high-resolution regional climate model simulation of the South Asian summer monsoon climatology. Int J Climatol 37:3630-3643

Lau KM, Kim MK, Kim KM (2006) Asian summer monsoon anomalies induced by aerosol direct forcing: the role of the Tibetan Plateau. Clim Dyn 26:855-864. https://doi.org/10.1007/s0038 2-006-0114-z

Li C, Yanai M (1996) The onset and interannual variability of the Asian summer monsoon in relation to land-sea thermal contrast. J Clim. https://doi.org/10.1175/1520-0442(1996)009\%3c0358:TOAIV $\mathrm{O} \% 3 \mathrm{e} 2.0 . \mathrm{CO} ; 2$

Lin Y-L, Farley RD, Orville HD (1983) Bulk parameterization of the snow field in a cloud model. J Clim Appl Meteorol 22:1065-1092

Ma D, Boos W, Kuang Z (2014) Effects of orography and surface heat fluxes on the South Asian summer monsoon. J Clim 27(17):66476659. https://doi.org/10.1175/JCLI-D-14-00138.1

Mei R, Ashfaq M, Rastogi D, Leung R, Dominguez F (2015) Dominating controls for wetter South Asian summer monsoon in the 21st century. J of Climate 28:3400-3419. https://doi.org/10.1175/ JCLI-D-14-00355.1

Park H-S, Chiang JCH, Bordoni S (2012) The mechanical impact of the Tibetan Plateau on the seasonal evolution of the South Asian monsoon. J Clim 25(7):2394-2407. https://doi.org/10.1175/JCLID-11-00281.1

Rana A, Nikulin G, Kjellström E, Strandberg G, Kupiainen M, Hansson U, Kolax M (2020) Contrasting regional and global climate simulations over South Asia. Clim. Dynam. 54:2883-2901. https ://doi.org/10.1007/s00382-020-05146-0

Rao BS, Rao DB, Rao VB (2004) Decreasing trend in the strength of Tropical Easterly Jet during the Asian summer monsoon season and the number of tropical cyclonic systems over Bay of Bengal. Geophys Res Lett 31:L14103

Rastogi D, Ashfaq M, Leung R, Ghosh S, Saha A, Hodges K, Evans K (2018) Characteristics of Bay of Bengal, monsoon depressions in the 21st century. Geophys Res Lett. https://doi.org/10.1029/2018G L078756

Schumacher C, Houze RA (2003) Stratiform rain in the tropics as seen by the TRMM precipitation radar. J Clim 16(11):1739-1756 
Singh D, Horton DE, Tsiang M, Haugen M, Ashfaq M, Mei R, Rastogi D, Johnson NC, Charland A, Rajaratnam B, Diffenbaugh NS (2014) Severe flooding in Northern India in June 2013: causes, historical context, and changes in likelihood, Bulletin of the American Meteorological Society [in "Explaining Extremes of 2013 from a Climate Perspective"]. Bull Am Meteorol Soc 95(9):S58-S61

Skamarock C, Klemp B, Dudhia J, Gill O, Barker D, Duda G, Huang X-Y, Wang W, Powers JG (2008) A description of the advanced research WRF version 3. https://doi.org/10.5065/D68S4MVH

Sperber KR et al (2013) The Asian summer monsoon: an intercomparison of CMIP5 vs. CMIP3 simulations of the late 20th century. Clim Dyn 41:2711-2744

WangHo BL (2002) Rainy season of the Asian-Pacific summer monsoon. J Clim 15:386-398

Webster PJ, Yang S (1992) Monsoon and ENSO: selectively interactive systems. Q J R Meteorol Soc 118:877-926

Webster PJ, Magaña VO, Palmer TN, Shukla J, Tomas RA, Yanai M, Yasunari T (1998) Monsoons: processes, predictability, and the prospects for prediction. J Geophys Res 103:14451-14510

Wei W, Zhang R, Wen M, Kim B-J, Nam J-C (2015) Interannual variation of the South Asian high and its relation with Indian and East Asian summer monsoon rainfall. J Clim 28:2623-2634. https:// doi.org/10.1175/JCLI-D-14-00454.1

Wu G, Zhang Y (1998) Tibetan Plateau forcing and the timing of the monsoon onset over South Asia and the South China Sea. Mon
Weather Rev 126(4):913-927. https://doi.org/10.1175/15200493(1998)126\%3c0913:TPFATT\%3e2.0.CO;2

Wu GX, Li WP, Guo H, Liu H (1997) Sensible heating-drive air pump of the Tibetan Plateau and the Asian summer monsoon. In: Ye DZ (ed) Memorial volume of Prof. JZ Zhao. Science Press, Beijing, pp 16-126

Wu G, Liu Y, He B et al (2012) Thermal controls on the Asian summer monsoon. Sci Rep 2:404. https://doi.org/10.1038/srep00404

Wu CH, Hsu HH, Chou MD (2014) Effect of the Arakan Mountains in the northwestern Indochina Peninsula on the late May Asian monsoon transition. J Geophys Res 119:10769-710779. https:// doi.org/10.1002/2014JD022024

Yanai M, Esbensen S, Chu JH (1973) Determination of bulk properties of tropical cloud clusters from large-scale heat and moisture budgets. J Atmos Sci 30(4):611-627. https://doi.org/10.1175/15200469(1973)030\%3c0611:Dobpot\%3e2.0.Co;2

Yanai M, Li C, Song Z (1992) Seasonal heating of the Tibetan Plateau and its effects on the evolution of the Asian summer monsoon. $\mathrm{J}$ Meteorol Soc Jpn Ser II 70(1B):319-351

Yang B, Zhang Y, Qian Y et al (2019) Better monsoon precipitation in coupled climate models due to bias compensation. npj Clim Atmos Sci 2:43. https://doi.org/10.1038/s41612-019-0100-x

Yatagai A et al (2012) APHRODITE: constructing a long-term daily gridded precipitation dataset for Asia based on a dense network of rain gauges. Bull Am Meteorol Soc 93:1401-1415 